\title{
PARTÍCULAS ARGILOMINERAIS NÃO INFLUENCIAM A VIABILIDADE DAS CÉLULAS-TRONCO DA CRISTA NEURAL
}

\author{
J. NONES ${ }^{1}$, J. NONES ${ }^{2}$, H.G. RIELLA ${ }^{1}$, N. C. KUHNEN ${ }^{1}$ e A.G. TRENTIN ${ }^{2}$ \\ ${ }^{1}$ Universidade Federal de Santa Catarina, Departamento de Engenharia Química e Engenharia \\ de Alimentos \\ ${ }^{2}$ Universidade Federal de Santa Catarina, Departamento de Biologia Celular Embriologia e \\ Genética \\ E-mail para contato: janaina.nones@posgrad.ufsc.br
}

\begin{abstract}
RESUMO - Partículas argilominerais apresentam inúmeras aplicações na indústria farmacêutica. Apesar de serem biotecnologicamente empregadas, seus efeitos sobre células-tronco da crista neural $(\mathrm{CN})$ permanecem desconhecidos. Considerando estes aspectos, o objetivo deste trabalho foi caracterizar quimicamente partículas argilominerais (bentonita) extraídas da região Sul de Santa Catarina, assim como verificar sua influência sobre a viabilidade e sobrevivência das células-tronco da CN. Para tal, essas partículas argilominerais foram caracterizadas por difração de raios-X e ensaios físico-químicos. A viabilidade e morte das células foram determinadas por MTT e análise dos núcleos picnóticos, respectivamente. Nossos resultados demonstraram que partículas argilominerais (bentonita $0,6 \mathrm{mg} / \mathrm{mL}$ ) não influenciam a viabilidade e a sobrevivência celular. Considerando as propriedades farmacológicas da bentonita, outros estudos deverão ser realizados com o intuito de avaliarmos seus efeitos em terapias envolvendo células-tronco.
\end{abstract}

\section{INTRODUÇÃO}

Bentonitas são argilas constituídas por partículas argilominerais. Estruturalmente são formadas por duas camadas de tetraedros de silício e uma camada de octaedro de alumínio (Bhuiyan et al., 2013). Possuem propriedades de capacidade de troca catiônica, adsorção, condutividade hidráulica e inchamento (Hanuláková et al., 2013). Devido a estas propriedades, as bentonitas são utilizadas para reduzir efeitos colaterais provocados por diversos fármacos (Abbès et al., 2008; Kevadiya, 2012). Além disso, suas propriedades químicas auxiliam na cura de feridas, aliviam irritações, protegem a pele contra substâncias químicas ou físicas e auxiliam no tratamento de distúrbios gastrointestinais (López-Galindo e Viseras, 2004; Valenti et al., 2012).

Embora já existam estudos sobre o efeito da bentonita em uma variedade de tipos celulares (Abbès et al., 2008; Zhang et al., 2010), não há informações disponíveis sobre os efeitos deste material em células-tronco da crista neural $(\mathrm{CN})$. As células da $\mathrm{CN}$ surgem durante o desenvolvimento dos vertebrados (Dupin et al., 2007) e são responsáveis pela 
formação de tecidos ósseos e cartilaginosos, além de originarem o sistema nervoso periférico (Avery et al., 2014).

Considerando estes aspectos, o objetivo deste trabalho foi caracterizar quimicamente partículas argilominerais (bentonita) extraídas de Santa Catarina, assim como verificar sua influência sobre a viabilidade e sobrevivência das células-tronco da $\mathrm{CN}$.

\section{MATERIAL E MÉTODOS}

\subsection{Material}

Amostras de bentonita: foram coletadas no município de Criciúma, Santa Catarina, região Sul do Brasil. Após coletadas, as amostras foram lavadas com água destilada para remoção de impurezas e, em seguida, secas em estufa a $60^{\circ} \mathrm{C}$, durante 8 horas.

Cultura de células: culturas de células da $\mathrm{CN}$ de codornas foram realizadas conforme indicado por Trentin et al. (2004). Os animais foram mantidos sob condições laboratoriais padronizadas, de acordo com o guia para o cuidado e uso de animais (NIH Publication No. 85-23, revisado 1985). Esses estudos foram aprovados pelo Comitê de Ética local de Pesquisa Animal ( ${ }^{\circ} 103$ e 787 CEUA/UFSC).

\subsection{Métodos}

Caracterização das bentonitas: (A) Difração de Raios-X (DRX): as medidas foram realizadas em um difratômetro Philips, modelo X'pert, com radiação cobre $K \alpha(\lambda=1,5418 \mathrm{~A})$, potência de $40 \mathrm{kV}$ e $30 \mathrm{~mA} .(B)$ Características físico-químicas: foram realizadas por diferentes técnicas laboratoriais, incluindo ensaios gravimétricos (umidade e perda ao fogo), visuais (cor), granulométricos (resíduo bruto) e de concentração (densidade). A refração linear e absorção d'água foram determinadas seguindo as metodologias descritas pela ABNT (1984) e ASTM (1988), respectivamente.

Ensaios de MTT: 3-(4,5-dimetiltiazol-2yl)-2,5-difenil brometo de tetrazolina (MTT) foi utilizado para análise da atividade mitocondrial. No ensaio, MTT foi reduzido a sal de formazan, colorido e insolúvel em água, pelo sistema succinato-tretazólio redutase, que pertence à cadeia respiratória mitocondrial. Para realização da técnica, células da $\mathrm{CN}$ foram cultivadas por um período de 24 horas na presença ou não de bentonita $(0,6 \mathrm{mg} / \mathrm{mL})$. MTT foi adicionado para cada poço em uma concentração final de $150 \mu \mathrm{g} / \mathrm{mL}$ e as células foram incubadas durante 2 horas à $37^{\circ} \mathrm{C}$. $\mathrm{O}$ produto da reação foi dissolvido com dimetil sulfóxido (DMSO) e quantificado através de leitura em espectrofotômetro Bio-Tek FL-600 Microplate Fluorescence Reader, em comprimento de onda de $540 \mathrm{~nm}$.

Ensaio de sobrevivência celular: a morte celular foi analisada através das avaliações morfológicas dos núcleos picnóticos (visualização da fragmentação da cromatina) através de marcação por DAPI (Nones et al., 2013). 


\section{RESULTADOS E DISCUSSÃO}

Diferentes formações geológicas podem afetar as propriedades químicas e físicas de argilas, como bentonitas. Por este motivo, as amostras de bentonita extraídas de Criciúma (Santa Catarina, Brasil) foram inicialmente caracterizadas através das técnicas de DRX e ensaios físico-químicos.

Nossos resultados de caracterização corroboraram com os dados de Devreese et al., (2012) e Sampatakakis et al. (2013), que também demonstraram a presença de picos de montmorillonita $(\mathrm{M})$, caulinita $(\mathrm{C})$, muscovita $\left(\mathrm{M}_{\mathrm{c}}\right)$ e quartzo(Q) (Figura 1).

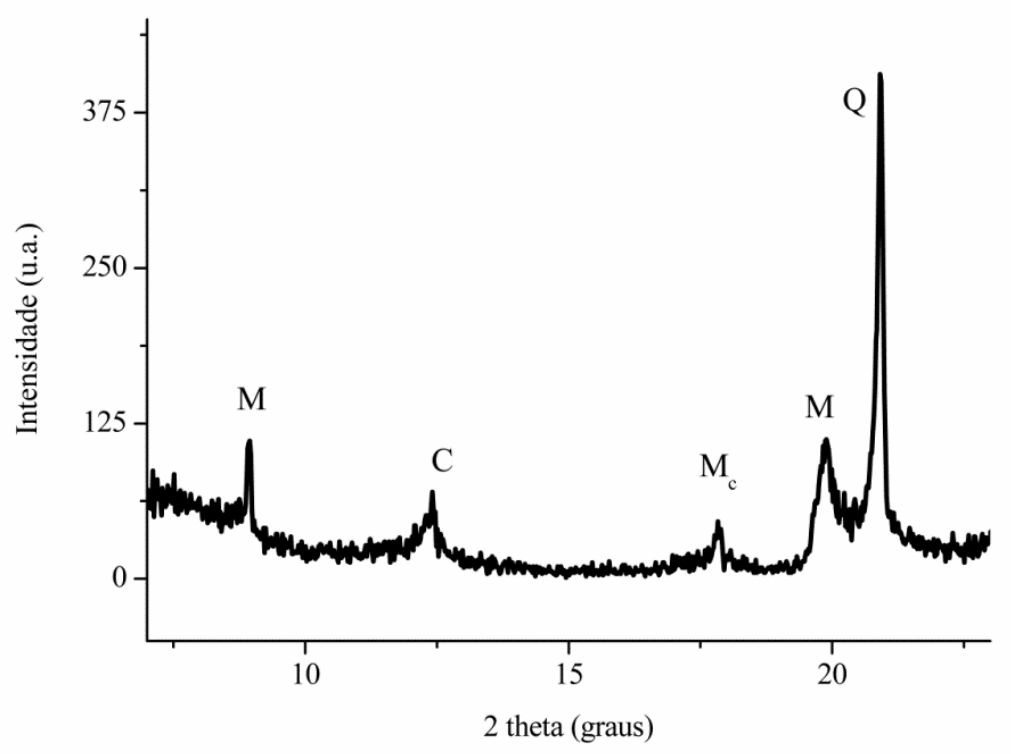

Figura 1. Difratograma de uma amostra de bentonita extraída da região Sul do Estado de Santa Catarina. Os minerais identificados na amostra foram: montmorillonita (M), caulinita $(C)$, muscovita $\left(\mathrm{M}_{\mathrm{c}}\right)$ e quartzo $(\mathrm{Q})$.

Após a realização da técnica de DRX, as amostras de bentonita foram submetidas a ensaios físico-químicos. Nestas análises, os resultados obtidos demonstraram que a densidade da bentonita foi de $1,87 \mathrm{~g} / \mathrm{cm}^{3}$, apresentando umidade $\leq 25,00 \%$ e perda ao fogo $\geq 5,00 \%$. Além disso, ensaios físico-químicos de refração linear, resíduo bruto, absorção d'água e cor de queima também foram analisados, conforme demonstrado na Tabela 1.

A determinação de propriedades físico-químicas é de fundamental importância para compreensão da interação das partículas com diferentes fluidos (Viotti, 2006), incluindo inclusive os que se encontram no meio celular. Por este motivo, após a realização destas caracterizações físico-químicas, partículas argilominerais foram adicionadas a culturas de células-tronco para avaliação da viabilidade celular, analisada através de ensaios de MTT. Nossos resultados não demonstraram alterações nos valores de absorbância após 4 dias de 
tratamento com 0,6 mg/mL de bentonita (91\% de absorbância), quando comparado com o grupo controle (100 \% de absorbância) (Figura 2).

Tabela 1. Características físico-químicas da amostra de bentonita proveniente de Santa Catarina

\begin{tabular}{lcc}
\hline Características & & Variações (+/-) \\
\hline Refração linear a $1160{ }^{\circ} \mathrm{C}$ & 3,00 a $4,00 \%$ & 0,80 \\
Absorção d'água a $1160{ }^{\circ} \mathrm{C}$ & 8,00 a $10,00 \%$ & 2,00 \\
Umidade & $\leq 25,00 \%$ & 2,00 \\
Resíduo Bruto \#200 & $\leq 20,00 \%$ & 5,00 \\
Densidade & $1,87 \mathrm{~g} / \mathrm{cm}^{3}$ & 0,09 \\
Cor de queima & Amarela escura & $\mathrm{NA}$ \\
Perda ao fogo a $1160{ }^{\circ} \mathrm{C}$ & $\geq 5,00 \%$ & 1,0 \\
\hline
\end{tabular}

NA. não aplicado

Este efeito sugere que partículas de bentonita na concentração empregada não gera citotoxicidade celular. No entanto, outros fatores precisarão ser avaliados para determinação da dosagem correta a ser empregada durante a realização de ensaios terapêuticos, como por exemplo, a avaliação do tempo de exposição (Maisanaba et al., 2013; Huang et al., 2013).

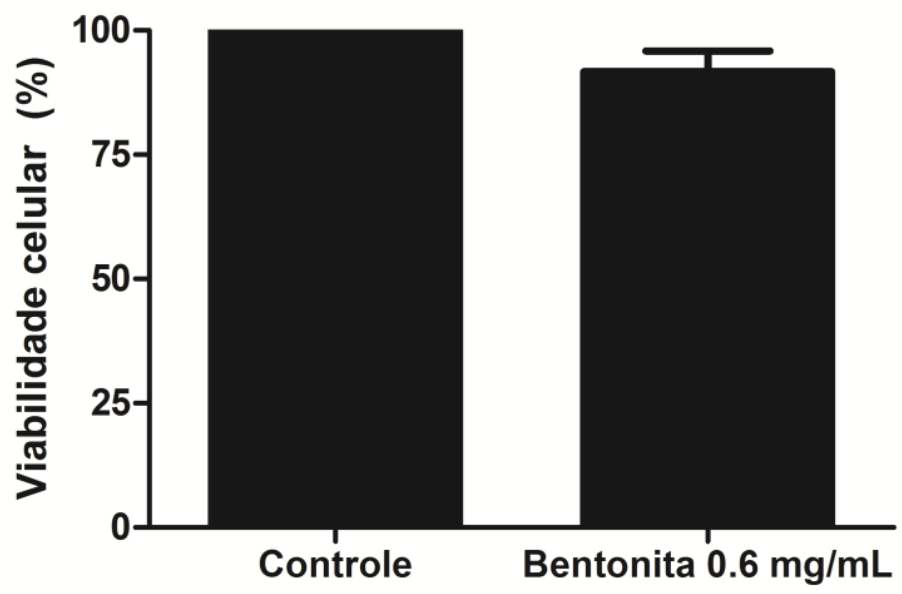

Figura 2. Bentonita não afeta a viabilidade das células da $\mathrm{CN}$. Culturas de células-tronco da CN de codornas foram incubadas com DMSO (grupo controle) ou com particulas argilominerais (bentonita 0,6 mg/mL). Após 4 dias de tratamento, a viabilidade celular foi analisada através das técnicas de MTT. Os resultados representam a média de três experimentos (triplicatas) independentes. ${ }^{*} \mathrm{P}<0,05$ quando comparado com o grupo controle.

Considerando os resultados de viabilidade obtidos, ambos os grupos experimentais citados acima (controle e bentonita na concentração de $0,6 \mathrm{mg} / \mathrm{mL}$ ) foram submetidos a análises dos núcleos picnóticos. Nossos resultados demonstraram que as células-tronco da $\mathrm{CN}$ tratadas com partículas argilominerais $(0,6 \mathrm{mg} / \mathrm{mL})$ não apresentaram nenhuma variação com relação ao grupo controle (Figura 3). 


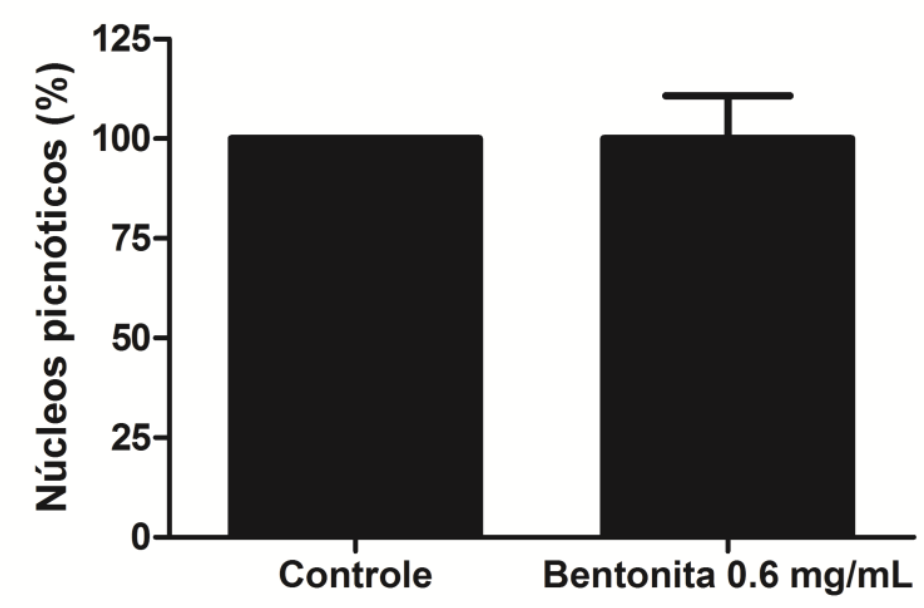

Figura 3. Bentonita não afeta a morte das células da $\mathrm{CN}$. Culturas secundárias de células da CN foram incubadas com DMSO (grupo controle) ou 0,6 mg/mL de bentonita. Após 4 dias de tratamento, a morte celular foi analisada por quantificação de células que apresentaram núcleos picnóticos. Os resultados representam a média de três experimentos independentes realizadas em triplicata \pm erro padrão. $* \mathrm{P}<0,05$ quando comparado com o grupo controle.

Através deste estudo podemos concluir que partículas argilominerais na concentração de $0,6 \mathrm{mg} / \mathrm{mL}$ não induzem a morte e não reduzem a viabilidade celular. Estes resultados sugerem que este material pode ser empregado em terapias envolvendo células-tronco, reduzindo os efeitos colaterais de determinados fármacos e/ou otimizando o tempo de cura de pacientes submetidos a estes tratamentos.

\section{REFERÊNCIAS BIBLIOGRÁFICAS}

ABBÈS, S.; SALAH-ABBÈS, J. B.; HETTA, M. M.; IBRAHIM, M.; ABDEL-WAHHAB, M.A.; BACHA, H.; OUESLATI, R. Efficacy of Tunisian montmorillonite for in vitro aflatoxin binding and in vivo amelioration of physiological alterations. Appl Clay Sci, v. 42, p. 151-157, 2008.

ABNT, NBR MB 305, Determinação da Retração Linear, (1984).

ASTM, C 378 - 88, Test Method for Water Absorption, Bulk Density, Apparent Porosity and Apparent Specific Gravity of Fired Whiteware Products, (1988).

AVERY, J.; MENENDEZ, L.; CUNNINGHAM, M. L.; LOVVORN, H. N.; DALTON, S. Using Induced Pluripotent Stem Cells as a Tool to Understand Neurocristopathies. Neural Crest Cells, Elsevier, 2014.

BHUIYAN, I. U.; MOUZON， J.; SCHRÖPPEL， B.; KAECH，A.; DOBRYDEN， I.; FORSMO, S. P.E.; HEDLUND, J Microsc Microanal, v.6, p.1-9, 2013. 
DEVREESE, M.; OSSELAERE, A.; GOOSSENS, J.; VANDENBROUCKE, V.; DE BAERE, S. DE BACKER, P.; CROUBELS, S. Interaction between tylosin and bentonite clay from a pharmacokinetic perspective. Vet J, v. 194, p.437-439, 2012.

DUPIN, E.; CALLONI, G. W.; REAL, C.; Trentin, A. G.; DOUARIN, N. L. Neural crest progenitors and stem cells. Comptes Rendus Biologies, v. 330, p. 521-529, 2007.

HANULÁKOVÁ, D.; ZEMAN, J.; VAŠÍČEK, R.; PŘIKRYL, R.; KUCHOVSKÝ, T. Determination of pore water composition during long term interaction of bentonite substrates with water media: comparative study. Appl Clay Sci, v.80-81, p. 69-75, 2013.

HUANG, Y.; ZHANG, M.; ZOU, H.; LI, X.; XING, M.; FANG, X.; HE, J. Genetic damage and lipid peroxidation in workers occupationally exposed to organic bentonite particles, Mutat Res, v. 751, p. 40-44, 2013.

KEVADIYA, B.D.; THUMBAR, R.P.; RAJPUT, M.M.; RAJKUMAR, S.; BRAMBHATT, H.; JOSHI, G.V.; DANGI, G.P.; MODY, H.M.; GADHIA, P.K.; BAJAJ, H.C. Montmorillonite/poly-( $\varepsilon$-caprolactone) composites as versatile layered material: reservoirs for anticancer drug and controlled release property. Eur J Pharm Sci, v. 47, p. 265-272, 2012.

LÓPEZ-GALINDO, A.; VISERAS, C. Pharmaceutical and cosmetic applications of clays, in: F. Wypych, K.G. Satyanarayana (Eds.), Clay Surfaces: Fundamentals and Applications, Elsevier, Armsterdam, 2004.

MAISANABA, S.; GUTIÉRREZ-PRAENA, D.; PICHARDO, S.; MORENO, F.J.; JORDÁ, M.; CAMEÁN, A.M.; AUCEJO, S.; JOS, A. Toxic effects of a modified montmorillonite clay on the human intestinal cell line Caco-2. J Appl Toxicol, v. 34, p. 1-12, 2013.

NONES, J.; NONES, J.; TRENTIN, A. Flavonoid hesperidin protects neural crest cells from death caused by aflatoxin $\mathrm{B}_{1}$. Cell Biol Int, v. 37, p. 181-186, 2013.

SAMPATAKAKIS, S.; LINOS, A.; PAPADIMITRIOU, E.; PETRALIAS, A.; DALMA, A.; PAPASARANTI, E.S.; CHRISTOFORIDOU, E.; STOLTIDIS, M. Respiratory disease related mortality and morbidity on an island of greece exposed to perlite and bentonite mining dust int. J Environ Res Public Health, v.10, p. 4982-4995, 2013.

TRENTIN, A.; GLAVIEUX-PARDANAUD, C.; LE DOUARIN, N.M.; DUPIN, E. Selfrenewal capacity is a widespread property of various types of NC precursor cells. Proc Natl. Acad Sci USA, v. 101, p.4495-500, 2004.

VALENTI, D.M.; SILVA, J.; TEODORO, W.R.; VELOSA, A.P.; MELLO, S.B. Effect of topical clay application on the synthesis of collagen in skin: an experimental study. Clin Exp Dermatol, v.37, p. 164-168, 2012.

VIOTTI G.C.A., Desenvolvimento e caracterização de argilas organofílicas para uso em alimentação animal como adsorvente inativador de micotoxinas: aflatoxina b1 e fumonisina b1. 2006. 216f. Tese (Doutor em Engenharia Química) - Programa de pósgraduação em Engenharia Química, UFSC, Florianópolis. 
ZHANG, M.; LU, Y.; LI, X.; CHEN, Q.; LU, L.; XING, M.; ZOU, H.; HE, J. Studying the cytotoxicity and oxidative stress induced by two kinds of bentonite particles on human B lymphoblast cells in vitro. Chem Biol Interact, v.183, p.390-396, 2010. 